\title{
Comment on the Specific Epithets in the Names Moraxella kingii Henriksen and $\mathrm{B} \emptyset \mathrm{vre}$ and Pseudomonas kingii Jonsson
}

\author{
ULRICH BERGER \\ Institute of Hygiene, University of Heidelberg, 69 Heidelberg, German Federal Republic \\ The specific epithets in the names Moraxella kingii Henriksen and $\mathrm{B} \phi \mathrm{vre}$ and \\ Pseudomonas kingii Jonsson were formed contrary to the Recommendations of \\ the International Code of Nomenclature of Bacteria. Epithets based on the \\ names of women should be formed according to the Recommendations of the \\ Code "to ensure greater uniformity and clearness." In addition, it is suggested \\ that the correct Latin genitive for women's names which end in a consonant is \\ formed by adding -iae, not merely -ae as recommended by the Code.
}

Recently two new bacterial species were described and named in honor of the late Elizabeth O. King: Moraxella kingii Henriksen and $\mathrm{B} \varnothing \mathrm{vre}(1)$ and Pseudomonas kingii Jonsson (2).

According to Recommendation $27 \mathrm{f}$ of the International Code of Nomenclature of Bacteria (4): "Provisions of Recommendation 27e apply to an epithet formed from the name of a woman. When the epithet has a substantival form, it is given a feminine ending." The pertinent part of Recommendation $27 \mathrm{e}$ reads as follows: "When the epithet is a substantive, the modernized Latin genitive is formed in the following manner:...(2) When the name ends in a consonant, the letters $-i i$ are added ... except when the name ends in $-e r$, when $-i$ is added." The previous edition of the Code (3) contained the following annotation to Recommendation 27f: "The genitives of names of women ending in a vowel other than $-a$ or that end in a consonant are formed by adding -ae." Clearly, the specific epithets kingii in the names Moraxella kingii and Pseudomonas kingii were formed in a manner contrary to that indicated in Recommendation $27 \mathrm{f}$.

The purpose of this paper is to bring attention to Recommendation $27 \mathrm{f}$ so that in the future specific epithets based on the names of women are formed in a suitable and consistent fashion.

At the same time, the correctness of adding merely ae to a woman's name to form the Latin genitive is questioned. Just as the nominative masculine Latin ending applied to a man's name which ends in a consonant is -ius (hence the genitive $-i i$ ), the analogous feminine ending in the nominative would be $-i a$, with the genitive -iae.

\section{LITERATURE CITED}

1. Henriksen, S. D., and K. Bøvre. 1968. Moraxella kingii sp. nov., a haemolytic, saccharolytic species of the genus Moraxella. J. Gen. Microbiol. 51:377-385.

2. Jonsson, V. 1970. Proposal of a new species Pseudomonas kingii. Int. J. Syst. Bacteriol. 20: 255-257.

3. International Code of Nomenclature of Bacteria. 1966. Int. J. Syst. Bacteriol. 16:459-490.

4. International Code of Nomenclature of Bacteria and Viruses. 1958. Iowa State College Press, Ames, Iowa. 